\title{
Transesterification of leather tanning waste to biodiesel at supercritical condition: Kinetics and thermodynamics studies
}

\author{
L.K. Ong ${ }^{\mathrm{a}, 1}$, A. Kurniawan ${ }^{\mathrm{a}, 1}$, A.C. Suwandi ${ }^{\mathrm{a}, 1}$, C.X. Lin ${ }^{\mathrm{b}}$, X.S. Zhao ${ }^{\mathrm{b}, *}$, S. Ismadji ${ }^{\mathrm{a}, * *}$ \\ a Department of Chemical Engineering, Widya Mandala Surabaya Catholic University, Kalijudan 37, Surabaya 60114, Indonesia \\ ${ }^{\mathrm{b}}$ School of Chemical Engineering, The University of Queensland, St. Lucia 4072, Qld, Australia
}

\section{A R T I C L E I N F O}

\section{Article history:}

Received 11 October 2012

Received in revised form

20 December 2012

Accepted 22 December 2012

\section{Keywords:}

Leather tanning waste

Supercritical condition

Kinetics

Thermodynamics

ACT

\begin{abstract}
A B S T R A C T
Catalyst-free transesterification of leather tanning waste with high free fatty acid (FFA) content at supercritical condition was reported in this work. The experiments were performed in batch system at various temperatures $\left(250-325^{\circ} \mathrm{C}\right)$ under constant pressure of $12 \mathrm{MPa}$ and methanol/fatty oil molar ratio of 40:1 for reaction time of $2-10 \mathrm{~min}$. Kinetic modeling of formation of fatty acid methyl esters (FAMEs) that incorporate reversible esterification and non-reversible transesterification simultaneously was verified. The proposed semi-empirical model was fitted against kinetic experimental data over temperature range studied. The kinetic parameters (i.e. $k_{\mathrm{TE}}^{\prime}, k_{\mathrm{E}}^{\prime}$, and $k_{\mathrm{E}}{ }^{\prime}$ ) were determined by nonlinear regression fitting. Thermodynamic activation parameters of the reactions were evaluated based on activation complex theory (ACT) and the following results are obtained: $\Delta G^{\ddagger}>0, \Delta H^{\ddagger}>0$, and $\Delta S^{\ddagger}<0$. The activation energy $\left(E_{a}\right)$ of transesterification, forward and reverse esterification reactions was $36.01 \mathrm{~kJ} / \mathrm{mol}, 28.38 \mathrm{~kJ} / \mathrm{mol}$, and $5.66 \mathrm{~kJ} / \mathrm{mol}$, respectively.
\end{abstract}

(C) 2012 Elsevier B.V. All rights reserved.

\section{Introduction}

The rising market price and the depleting reserves of world crude oil have become the main reasons behind the search and development of alternative fuels, particularly for transportation and industrial purposes. Biodiesel (BD) is regarded as a promising alternative liquid biofuel to displace petro-diesel fuel that will be fully exhausted in near future. It is biodegradable, low toxicity, and produces much cleaner combustion compared to petro-diesel fuel with significant reduction of carbon monoxide, unburned hydrocarbons, and particulate matters (e.g., aldehydes, fume, and suspension particles) emissions about 50\%, 70\%, and 50\%, respectively [1]. Biodiesel can be also blended with petro-diesel fuel in various proportions to provide similarity in terms of energy density and kinematic viscosity for direct use in the existing engines without extensive modifications. Because of its benefits, the development of biodiesel worldwide has rapidly grown annually [2].

Biodiesel is composed of a mixture of alkyl esters that mostly produced by esterification and/or transesterification (or alcoholysis) of various lipid feedstocks such as vegetable oils [3-5] and

\footnotetext{
* Corresponding author. Tel.: +61 73346 9997; fax: +61 733654199

** Corresponding author. Tel.: +62 31389 1264; fax: +62 312891267.

E-mail addresses: george.zhao@uq.edu.au (X.S. Zhao),

suryadiismadji@yahoo.com, a1f1n_kwn@yahoo.com (S. Ismadji).

1 These authors contributed equally to this work.
}

animal fats [6,7] with methanol or ethanol as the reacting alcohol. However, the use of vegetable oils and animal fats as biodiesel feedstocks causes economic issues for industrial and commercial practices, associated with the market price of these feedstocks that accounts for $75-85 \%$ from the overall production cost [8]. Moreover, some of vegetables oils (e.g., palm oil, coconut oil, and soybean oil) and animal fats (e.g., beef tallow, lamb, and chicken fats) are edible hence causes an intense competition with the food industries. Recently, researches have been directed toward the utilisation of non-edible and low cost feedstocks with high lipid content for biodiesel production such as leather tanning waste. The availability of tannery waste is huge in several countries with total production in Indonesia reached 0.15 million tons annually. The disposal and accumulation of this waste in the environment are of great concerns due to its unpleasant odor and adverse impacts on the soil fertility and water quality. Therefore, there is of interest to manage leather tanning waste properly and one advantageous way is by converting them to biodiesel.

The most extensively used methods to produce biodiesel from leather tanning waste are through one-step and/or two-step transesterification using acid and alkaline catalysts [9-11]. In the case of the former, the process is usually conducted using an alkaline catalyst to directly convert triglyceride into alkyl ester. However, the alkali-catalyzed transesterification is very sensitive to high free fatty acid (FFA) and water contents because the catalyst can saponify FFA to soap that prevents separation of biodiesel from the mixture and lowers biodiesel yield. Therefore, this method 
only appropriately used for refined feedstocks with low levels of FFA and water, preferably lower than $1 \mathrm{wt} . \%$ and $0.06 \mathrm{wt} . \%$, respectively [12]. For acid-catalyzed method, the process was performed in two-step where triglyceride contents in the feedstock are firstly hydrolyzed into monoglycerides, followed by esterification of monoglycerides into alkyl esters. However, this process is timeconsuming because the reaction proceeds very slow and requires acid-resistant equipments. Recently, supercritical transesterification (SC-TE) has been highlighted as an emerging technology for biodiesel production from various feedstocks including leathertanning waste. This method is able to completely convert fatty acids in feedstock to alkyl ester in a relatively short time without involving any catalyts and offers simple product separation from the mixture. Furthermore, supercritical transesterification method can tolerate FFA and water contents in the feedstock up to $30 \mathrm{wt} . \%$ and $36 \mathrm{wt} . \%$, respectively [13]. In general, the production of biodiesel from vegetable oils or animal fats by supercritical alcohol transesterification was conducted at temperatures of $250-400^{\circ} \mathrm{C}$, pressures of $10-45 \mathrm{MPa}$, and molar ratio of alcohol to oil ranging from 40:1 to 50:1, as reported by Sawangkeaw et al. [14] in their review paper. However, the major drawbacks of this method are the extreme reaction condition concerning the use of high operating pressures and temperatures that require a specialized reactor design and considerable high alcohol/lipid molar ratio used in the process, which may pose technical and economical constraints for practical applications. Several innovative technologies have been suggested by Sawangkeaw et al. [14] in order to conduct supercritical transesterification reaction at milder condition and make this technique more feasible for industrial practice such as using co-solvents (e.g. $\mathrm{CO}_{2}$ or propane) or acid and base catalysts or modifying the SC-TE reaction system involving the use of two-step (subcritical hydrolysis-supercritical methanol esterification) [15] or dual-reactor process [16].

Although catalyst-free biodiesel production by supercritical alcohols has been well researched over past few years, the kinetics of reaction still needs to be studied in conjunction with several controversies in modeling the reaction kinetics by different approaches and the lack of available kinetic data over wide range of pressures and temperatures for industrial process operation and optimization. Several studies have reported the kinetic modeling of supercritical transesterification in batch, semi-batch, or continuous mode from various kinds of feedstocks [17-21]. Kusdiana and Saka [19] studied the batch transesterification of rapeseed oil to biodiesel by supercritical methanol and proposed the reaction kinetics by ignoring intermediate reactions (i.e. formation of diglyceride and monoglyceride). He et al. [20] also deal with the kinetics of transesterification of soybean oil by supercritical methanol under the same approaches used by Kusdiana and Saka [19], i.e. single step transesterification of triglycerides to fatty acid methyl esters (FAMEs) and the reaction is non-reversible and first-order with respect to triglyceride concentration. The transesterification kinetics of refined sunflower oil in supercritical methanol at various pressures and temperatures has been studied by Glisic and Orlovic [21]. They report that transesterification of sunflower oil to biodiesel takes place as three stepwise and parallel reversible reactions. However, most of the previous studies including the aforesaid investigate the kinetics of supercritical transesterification reaction using refined vegetable oils where esterification of free fatty acids (FFAs) to monoalkyl esters is not taken into account. For unrefined (or low-grade) feedstocks with high FFA content, esterification reaction should be incorporated in modeling the kinetics with respect to the formation of monoalkyl esters.

In the present work, we develop semi-empirical kinetic model of formation of fatty acid methyl esters at supercritical condition that incorporates non-reversible transesterification and reversible esterification simultaneously. Leather tanning waste and methanol

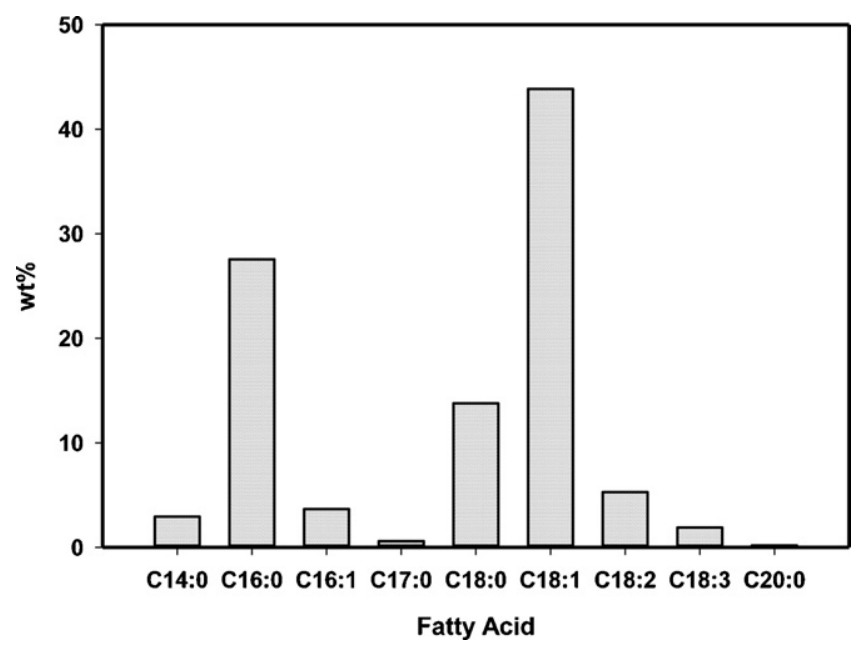

Fig. 1. Fatty acid compositions of leather tanning waste.

were employed as the model compound representing unrefined feedstock and reacting alcohol, respectively. The effects of temperature on the kinetic parameters (i.e. rate constants) were discussed. A simple technique for determining rate constants by nonlinear regression fitting was applied. Furthermore, thermodynamics of the reactions (i.e. $\Delta G^{\ddagger}, \Delta H^{\ddagger}$, and $\Delta S^{\ddagger}$ ) were evaluated on the basis of activation complex theory (ACT).

\section{Materials and methods}

\subsection{Materials}

The pre-fleshing fat waste as the raw material to produce biodiesel in this work was collected from a leather-tanning factory located at Bogor, West Java, Indonesia. Prior to use, the waste was repeatedly washed with deionized water to remove unwanted components including dirt, blood, preservative salt, etc. Subsequently, the waste was heated at $100^{\circ} \mathrm{C}$ for $1 \mathrm{~h}$ to remove water and then filtered to remove remaining flesh. The fatty acid compositions of fatty oil were analyzed by a Shimadzu GC-2014 equipped with a Restek Rtx-65TG fused silica capillary column $(30 \mathrm{~m} \times 0.25 \mathrm{~mm} \times 0.10 \mu \mathrm{m})$ and a flame ionization detector (FID) and the result are shown in Fig. 1. The free fatty acid content of fat waste was 14.9\%, as determined by ASTM D5555-95 method.

Anhydrous methanol (99.8\%) and heptane (99\%) were purchased from Merck, Germany. N-methyl- $N$ (trimethylsilyl)trifluoroacetamide (MSTFA) silylation reagent was purchased from Fluka as derivatization grade. The commercial stock solutions of triolein, 1,3-diolein, monoolein, and standard kit of Supelco ${ }^{\circledR} 37$ component FAME-mix were supplied from Sigma-Aldrich, Singapore and used for the preparation of calibration curves for the quantification of acylglycerides and FAME contents, respectively. Methyl heptadecanoate (99.5\%, Fluka) and tricaprin (Sigma-Aldrich) were used as internal standards for the analysis of fatty acid methyl esters and acylglycerides, respectively.

\subsection{Supercritical methanol transesterification}

The schematic of apparatus set-up for supercritical transesterification experiments is displayed in Fig. 2. The reaction system consists of a $50 \mathrm{ml}$ high pressure batch reactor, fittings and tubings, which made from 316-grade stainless steel, a K-type thermocouple for sensing temperature, a pressure gauge, and an external electric heater. The reactor was also connected to a cylinder gas containing nitrogen (99.99\%) at $15 \mathrm{MPa}$. 


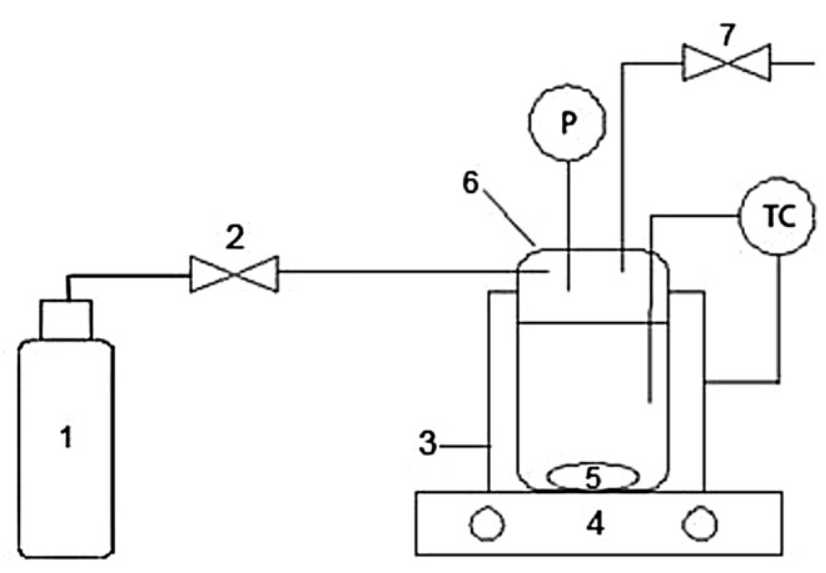

Fig. 2. The schematic of apparatus set-up for supercritical transesterification experiments. ( $\mathrm{N}_{2}$ cylinder (1); relief valve (2); electric heater (3); RPM controller (4); magnetic bar (5); reactor (6); and release valve (7)).

The procedure was described as follows: a certain proportion of methanol and fatty oil was loaded to the reactor to give methanol/fatty oil molar ratio of 40:1. A specified amount of nitrogen was then purged to the system. The reaction was conducted by rapidly heating methanol-fatty oil mixture from room temperature (around $30^{\circ} \mathrm{C}$ ) to desired temperatures $\left(250^{\circ} \mathrm{C}, 275^{\circ} \mathrm{C}, 300^{\circ} \mathrm{C}\right.$, and $325^{\circ} \mathrm{C}$ ). After temperature and pressure in the system reached the desired values, the reaction was held for a prescribed time ( $2 \mathrm{~min}$, $4 \mathrm{~min}, 6 \mathrm{~min}, 8 \mathrm{~min}$, and $10 \mathrm{~min}$ ). During this period, the pressure was monitored by a pressure gauge and the temperature was adjusted within $\pm 2{ }^{\circ} \mathrm{C}$ from the set-value by a PID-type controller for maintaining isobar and isothermal conditions. The reactor was then immersed in a water bath to stop the reaction immediately. The mixture was removed from the vessel and settled in a separation funnel overnight for phase separation between biodiesel (fatty acid methyl esters) and glycerol. The methyl ester-rich phase (top layer) was taken and underwent vacuum evaporation for $3 \mathrm{~h}$. The resulted product was analyzed to determine the concentrations of residual free fatty acids and acylglycerides and fatty acid methyl esters. All experimental data were reproduced by triplicate experiments with average used as the results.

\subsection{Biodiesel analyses}

Biodiesel analyses in this work were addressed to determine fatty acid methyl ester contents and concentrations of acylglycerides (tri-, di-, and monoglycerides) and FFA after the reaction completed. The free fatty acid content in the biodiesel samples was determined by titration against standardized $\mathrm{KOH}$ solution by following ASTM D5555-95 procedure. The acylglycerides and methyl ester contents in the sample were quantified by gas chromatography technique, as described below.

\subsubsection{Analysis of fatty acid methyl esters}

The fatty acid methyl esters in biodiesel were analyzed by a Shimadzu GC-2014 equipped with an Agilent narrowbore DB-Wax capillary column $(30 \mathrm{~m} \times 0.25 \mathrm{~mm} \times 0.25 \mu \mathrm{m})$ and a FID. Helium was used as carrier gas at pressure of $37.3 \mathrm{kPa}$ and column flow of $2.30 \mathrm{ml} / \mathrm{min}$. The temperatures of injector and FID were operated at $250{ }^{\circ} \mathrm{C}$ and $300^{\circ} \mathrm{C}$, respectively. The oven was programmed at $50^{\circ} \mathrm{C}$ for $2 \mathrm{~min}$, ramped at $10^{\circ} \mathrm{C} / \mathrm{min}$ to $250^{\circ} \mathrm{C}$ and hold isothermally for $8 \mathrm{~min}$. The sample injection volume was $1 \mu \mathrm{l}$ in splitless mode. Prior to injection, the sample was mixed with a certain amount of $100 \mathrm{mg} / \mathrm{ml}$ methyl heptadecanoate internal standard solution and diluted with heptane. The resulted methyl ester peaks in the sample were identified by comparing their retention time with the reference standards.

\subsubsection{Analysis of acylglycerides}

The concentrations of residual acylglycerides in biodiesel were determined by GC analysis, using an Agilent widebore DB-5HT $(15 \mathrm{~m} \times 0.32 \mathrm{~mm} \times 0.1 \mu \mathrm{m})$ high temperature capillary column by adopting ASTM D6584 method. The calibration solutions were prepared based on the ASTM D6584 procedure. Prior to injection, a known amount of tricaprin internal standard solution was added to the sample, derivatized with MSTFA, and diluted in heptane. The gas chromatography conditions for analysis of acylglycerides were as follows: Carrier gas: helium at column flow of $3 \mathrm{ml} / \mathrm{min}$ and pressure of $169.4 \mathrm{kPa}$; injector and FID temperatures were $360^{\circ} \mathrm{C}$ and $380^{\circ} \mathrm{C}$, respectively; The column oven temperature was set at $50^{\circ} \mathrm{C}$ for $1 \mathrm{~min}$, ramped at $15^{\circ} \mathrm{C} / \mathrm{min}$ to $180^{\circ} \mathrm{C}$, then elevated to $230^{\circ} \mathrm{C}$ at $7^{\circ} \mathrm{C} / \mathrm{min}$, and finally ramped to $380^{\circ} \mathrm{C}$ at $30^{\circ} \mathrm{C} / \mathrm{min}$ and maintain for $10 \mathrm{~min}$. The injection volume of sample was $1 \mu \mathrm{l}$ with a split ratio of 30:1. Identification of acylglycerides peaks was performed by the same manner as those of methyl ester peaks. The mass percentage of individual glycerides in the sample was calculated by following equation:

Acylglycerides (wt.\%) $=100\left(\frac{\left(a_{0} \times{ }^{A_{\mathrm{AG}} / A_{\mathrm{int}}}+b\right) \times V_{\mathrm{int}} \times C_{\mathrm{int}}}{m}\right)$

where $a_{0}$ and $b$ are the slope and the intercept of calibration curves of mono-, di-, and triglycerides, respectively, $V_{\text {int }}$ is the volume of tricaprin solution added to the sample $(\mathrm{ml}), C_{\text {int }}$ is the concentration of tricaprin solution ( $\mathrm{mg} / \mathrm{ml})$, and $m$ is the mass of the sample ( $\mathrm{mg}$ ). The peak areas of acylglycerides and tricaprin internal standard were symbolized as $A_{\mathrm{AG}}$ and $A_{\text {int }}$, respectively and designated as the response ratio $\left(A_{\mathrm{AG}} / A_{\text {int }}\right)$ in Eq. (1) based on the ASTM D6584 method.

\section{Results and discussion}

\subsection{Kinetic modeling}

Transesterification is a transformation reaction of fatty acid esters (e.g. oil or fat) to monoalkyl esters through an interchange of alkyl group between triglycerides and short-chain alcohol (e.g. methanol or ethanol) that occurs in three consecutive steps: (i) transformation of triglyceride (TG) to diglycerides (DG) and monoalkyl esters, (ii) transformation of DG to monoglyceride (MG) and monoalkyl esters, and (iii) transformation of MG to monoalkyl esters and glycerol. In this work, the kinetic evaluation of transesterification of leather tanning waste in batch system was performed using experimental data over temperature range of $250-325^{\circ} \mathrm{C}$ and reaction time of $2-10 \mathrm{~min}$ at constant methanol/oil molar ratio of $40: 1$ and pressure of $12 \mathrm{MPa}$. The existence of single phase of methanol-fatty oil mixture strongly depends on the applied pressure and temperature to the system hence it is necessary to verify the critical point of the mixture. For this purpose, Lee-Kesler method was used to estimate the critical properties (i.e. $P_{c}$ and $T_{c}$ ) of pure fatty oil due to the unavailability of thermophysical data of this substance. For simplification purpose, the mixture of saturated and unsaturated triglycerides in fatty oil was assumed as a single pseudo-triacylglyceride with equal molecular weight and degree of unsaturation of the original oil based on the approach taken in some previous studies [22-24]. The critical properties of methanol-fatty oil mixture were estimated by constructing phase diagram using Phase Envelope feature in ChemCAD software (Version 6.2.0, Chemstations Inc.) with Predictive Soave-Redlich-Kwong (PSRK) as the thermodynamic model. This group contribution equation of state was recommended by ChemCAD Wizard for the estimation of 


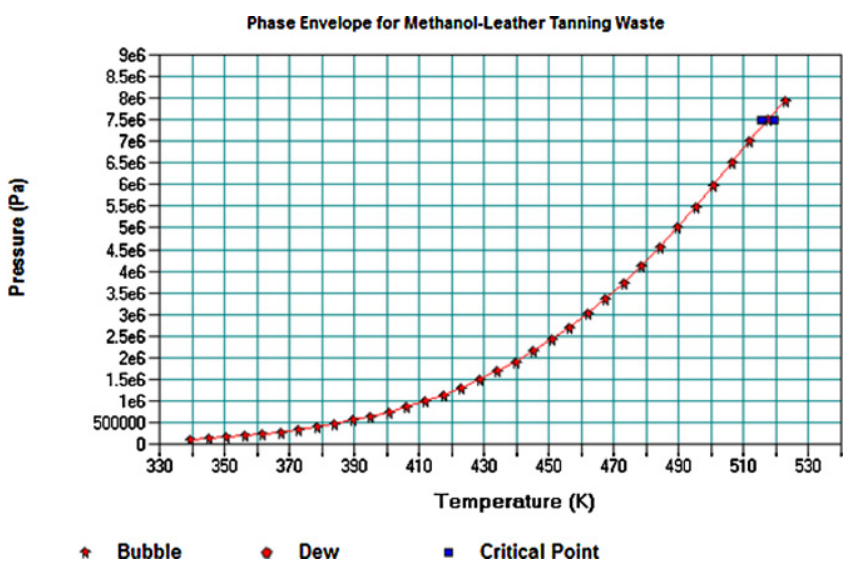

Fig. 3. Phase diagram and critical point of supercritical mixture of methanol-fatty oil with a molar ratio of 40:1.

thermophysical properties of a mixture containing supercritical components [25]. It can be seen from a phase diagram in Fig. 3 that the critical pressure and critical temperature of methanol-fatty oil mixture with a molar ratio of $40: 1$ are $7.49 \mathrm{MPa}$ and $244.04^{\circ} \mathrm{C}$, respectively. Hence, it is verified that pressure of $12 \mathrm{MPa}$ and temperatures ranging from $250^{\circ} \mathrm{C}$ to $325^{\circ} \mathrm{C}$ used in this study are sufficient to generate supercritical mixture of methanol and fatty oil with a molar ratio of $40: 1$. In order to simplify the complex behavior of transesterification reaction, several approaches were applied in modeling the reaction kinetics with respect to the formation of fatty acid methyl esters:

i. The overall supercritical transesterification reaction is irreversible according to the work reported by Marulanda et al. [26] hence the three consecutive steps of transformations of triglycerides to fatty acid methyl esters were indeed to be irreversible.

ii. The concentration change of methanol was ignored because methanol/fat molar ratio loaded to the system (40:1) is sufficiently high relative to the stoichiometric amount of methanol consumed by triglycerides (3:1) to undergo methanolysis reaction. Under this assumption, the overall supercritical transesterification reaction is presumed to be pseudo-first order with respect to triglyceride concentration alone.

iii. The extent of glycerol-methanol reactions was ignored relative to the formation of fatty acid methyl esters.

The kinetic representations of transesterification based on several approaches above were presented as follows:

$\mathrm{TG}+\mathrm{MeOH} \stackrel{k_{1}}{\rightarrow} \mathrm{DG}+\mathrm{FAME}$

$\mathrm{DG}+\mathrm{MeOH} \stackrel{k_{2}}{\rightarrow} \mathrm{MG}+\mathrm{FAME}$

$\mathrm{MG}+\mathrm{MeOH} \stackrel{k_{3}}{\rightarrow} \mathrm{FAME}+$ glycerol

The overall transesterification reaction (summation of Eq. (2) to Eq. (4)):

$\mathrm{TG}+3 \mathrm{MeOH} \stackrel{k_{\mathrm{TE}}}{\rightarrow} 3 \mathrm{FAME}+$ glycerol

Because leather tanning waste used in this work contains high portion of FFA (14.9\%), esterification reaction of FFAs to fatty acid methyl esters was taken into account:

$\mathrm{FFA}+\mathrm{MeOH} \underset{k_{\mathrm{E}}}{\stackrel{k_{\mathrm{E}}}{\leftrightarrows}} \mathrm{FAME}+\mathrm{H}_{2} \mathrm{O}$

From Eq. (6), it is apparent that water is accumulated in the system during the reaction hence hydrolysis reactions of TG and FAME species are expected to be occurred. However, the extent of these reactions can be presumed to be minor regarding the steric hindrance factor, which defined as the retardation of chemical reaction due to large size or overcrowded groups in the reacting molecules. Because triglycerides have more complex molecular structure than methyl esters, higher value of steric hindrance is expected for such molecules. Therefore, the extent of hydrolysis of triglycerides is neglected relative to that of hydrolysis of methyl esters, owing to higher steric hindrance in the former reaction. The rate equation forms of Eqs. (2)-(6) can be written as follows:

$-r_{\mathrm{TG}}=k_{1}[\mathrm{TG}][\mathrm{MeOH}]$

$-r_{\mathrm{DG}}=k_{2}[\mathrm{DG}][\mathrm{MeOH}]-k_{1}[\mathrm{TG}][\mathrm{MeOH}]$

$-r_{\mathrm{MG}}=k_{3}[\mathrm{MG}][\mathrm{MeOH}]-k_{2}[\mathrm{DG}][\mathrm{MeOH}]$

Since DG and MG are intermediate species, which immediately reacted with methanol, the notations of $-r_{\mathrm{DG}}$ and $-r_{\mathrm{MG}}$ can be presumed to be zero (i.e. quasi steady-state assumption). This assumption was supported from GC analysis results that show no considerable change on the concentrations of mono- and diglycerides at the initial and the end of reaction time.

$$
\begin{aligned}
-r_{\mathrm{DG}} & =0=k_{2}[\mathrm{DG}][\mathrm{MeOH}]-k_{1}[\mathrm{TG}][\mathrm{MeOH}] \Rightarrow k_{1}[\mathrm{TG}][\mathrm{MeOH}] \\
& =k_{2}[\mathrm{DG}][\mathrm{MeOH}]
\end{aligned}
$$

$$
\begin{aligned}
-r_{\mathrm{MG}} & =0=k_{3}[\mathrm{MG}][\mathrm{MeOH}]-k_{2}[\mathrm{DG}][\mathrm{MeOH}] \Rightarrow k_{2}[\mathrm{DG}][\mathrm{MeOH}] \\
& =k_{3}[\mathrm{MG}][\mathrm{MeOH}]
\end{aligned}
$$

The rate of formation of methyl esters $\left(r_{\mathrm{FAME}}\right)$ from transesterification reaction:

$$
\begin{aligned}
r_{\mathrm{FAME}}= & -r_{\mathrm{MeOH}}=k_{1}[\mathrm{TG}][\mathrm{MeOH}]+k_{2}[\mathrm{DG}][\mathrm{MeOH}] \\
& +k_{3}[\mathrm{MG}][\mathrm{MeOH}]
\end{aligned}
$$

Substitutes the term of $k_{2}[\mathrm{DG}][\mathrm{MeOH}]$ and $k_{3}[\mathrm{MG}][\mathrm{MeOH}]$ in Eq (12) with $k_{1}[\mathrm{TG}][\mathrm{MeOH}]$ as expressed in Eqs. (10) and (11) give:

$$
\begin{aligned}
r_{\mathrm{FAME}} & =-r_{\mathrm{MeOH}}=3 k_{1}[\mathrm{TG}][\mathrm{MeOH}], \quad \text { with } 3 k_{1}=k_{\mathrm{TE}} \text { and }[\mathrm{TG}] \\
& =\left[\mathrm{TG}_{\text {init }}\right]-X_{\mathrm{TG}}
\end{aligned}
$$

where $X_{\mathrm{TG}}$ is the amount of triglycerides converted to methyl esters $\left(\mathrm{moll}^{-1}\right)$. The rate of formation of methyl esters $\left(r_{\mathrm{FAME}}^{\prime}\right)$ from esterification reaction:

$r_{\mathrm{FAME}}^{\prime}=-r_{\mathrm{MeOH}}=k_{\mathrm{E}}[\mathrm{FFA}][\mathrm{MeOH}]-k_{\mathrm{E}}^{\prime}[\mathrm{FAME}]\left[\mathrm{H}_{2} \mathrm{O}\right]$

The term of [FFA] and $\left[\mathrm{H}_{2} \mathrm{O}\right]$ in Eq. (14) can be expressed as $[\mathrm{FFA}]=\left[\mathrm{FFA}_{\text {init }}\right]-X_{\mathrm{FFA}}$ and $\left[\mathrm{H}_{2} \mathrm{O}\right]=\left[\mathrm{H}_{2} \mathrm{O}_{\text {init }}\right]+X_{\mathrm{FFA}}$, respectively, where $X_{\mathrm{FFA}}$ is the amount of FFA converted to FAME $\left(\mathrm{moll}^{-1}\right)$. The concentration of FAME in the system can be stoichiometrically expressed as $[\mathrm{FAME}]=\left[\mathrm{FAME}_{\mathrm{init}}\right]+X_{\mathrm{FFA}}+3 X_{\mathrm{TG}}$ regarding esterification and transesterification reactions. The validity of stoichiometric equation above was assessed through comparison between calculated (represented as lines) and experimental FAME (represented as symbols) concentrations, as depicted in Fig. 4. It was found that the experimental and theoretical FAME values were slightly different (with average errors about 5\% at all temperatures), revealing the validity of equation to be used for kinetic modeling.

At initial reaction time $(t=0)$ or immediately after the system reached the desired pressure and temperature, the concentrations of fatty acid methyl esters ([FAME $\left.\left.E_{\text {init }}\right]\right)$ and water $\left(\left[\mathrm{H}_{2} \mathrm{O}_{\text {init }}\right]\right)$ in the system were analyzed to investigate the extent of transesterification and esterification reactions during heating time. From GC analysis results (see Fig. 5), it can be seen that the extent of FAME formation was not significant. A plausible explanation to this point is that during the heating time, the mixture still existed in two 


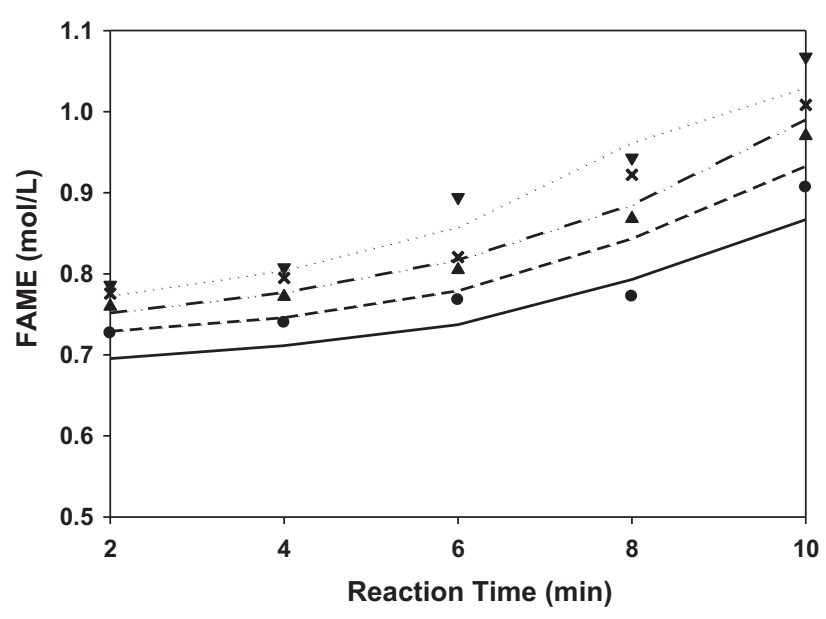

Fig. 4. Comparison plots between calculated (lines) and experimental (symbols) FAME concentrations in the reaction system $\left((\bullet) 250^{\circ} \mathrm{C} ;(\boldsymbol{\Delta}) 275^{\circ} \mathrm{C} ;(\times) 300^{\circ} \mathrm{C}\right.$; and ( v) $325^{\circ} \mathrm{C}$ ).

phases due to poor miscibility of methanol in the fatty oil and the absence of stirring action. Accordingly, the formation of methyl esters was restricted and it only took place in the interface area between methanol and fatty oil. Besides, a rapid heating rate also minimized the time available for the occurring reactions. Hence, the notations of [FAME $\left.E_{\text {init }}\right]$ and $\left[\mathrm{H}_{2} \mathrm{O}_{\text {init }}\right]$ can be presumed to be zero. Substituting the term of $\left[\mathrm{FFA}_{\text {init }}\right]-X_{\mathrm{FFA}}$ into [FFA]; $\left[\mathrm{H}_{2} \mathrm{O}_{\text {init }}\right]+X_{\mathrm{FFA}}$ into $\left[\mathrm{H}_{2} \mathrm{O}\right]$; and $\left[\mathrm{FAME}_{\text {init }}\right]+X_{\mathrm{FFA}}+3 X_{\mathrm{TG}}$ into [FAME] in Eq. (14), the following equation was obtained:

$$
\begin{aligned}
r_{\mathrm{FAME}}^{\prime}= & -r_{\mathrm{MeOH}}=k_{\mathrm{E}}\left[\mathrm{FFA}_{\text {init }}-X_{\mathrm{FFA}}\right][\mathrm{MeOH}] \\
& -k_{\mathrm{E}}^{\prime}\left[X_{\mathrm{FFA}}+3 X_{\mathrm{TG}}\right]\left[X_{\mathrm{FFA}}\right]
\end{aligned}
$$

By combining the rate of formation of FAME in Eqs. (13) and (15) give:

$$
\begin{aligned}
r_{\mathrm{FAME}}^{\prime \prime}-r_{\mathrm{MeOH}}= & k_{\mathrm{TE}}[\mathrm{TG}][\mathrm{MeOH}]+k_{\mathrm{E}}\left[\mathrm{FFA}_{\mathrm{init}}-X_{\mathrm{FFA}}\right][\mathrm{MeOH}] \\
& -k_{\mathrm{E}}^{\prime}\left[X_{\mathrm{FFA}}+3 X_{\mathrm{TG}}\right]\left[X_{\mathrm{FFA}}\right]
\end{aligned}
$$

Because the concentration change of methanol was neglected, Eq. (16) can be simplified to:

$$
\begin{aligned}
r_{\mathrm{FAME}}^{\prime \prime}= & -r_{\mathrm{MeOH}}=k_{\mathrm{TE}}^{\prime}\left[\mathrm{TG}_{\text {init }}-X_{\mathrm{TG}}\right] \\
& +k_{E}^{\prime}\left[\mathrm{FFA}_{\text {init }}-X_{\mathrm{FFA}}\right] k_{\mathrm{E}}^{\prime}\left[X_{\mathrm{FFA}}+3 X_{\mathrm{TG}}\right]\left[X_{\mathrm{FFA}}\right]
\end{aligned}
$$

where $\left[\mathrm{TG}_{\text {init }}\right]$ and $\left[\mathrm{FFA}_{\text {init }}\right]$ are the initial concentrations of triglyceride and free fatty acid, respectively, in the unit of $\mathrm{moll}^{-1}$. The reaction rate constants of $k^{\prime} \mathrm{TE}$ and $k_{\mathrm{E}}^{\prime}\left(\mathrm{min}^{-1}\right)$ were designated as the rate constant of transesterification and forward esterification multiplied by concentration of methanol. The rate equation in Eq. (17) was proposed as semi-empirical kinetic model that incorporates reversible esterification and non-reversible transesterification reactions simultaneously.

The molar concentration of fatty acid methyl esters $\left(\mathrm{moll}^{-1}\right)$ was calculated by dividing the peak area of each fatty acid methyl ester species with its corresponding molecular weight then multiplied by the density of product. The values of $r_{\text {FAME }}$ were calculated by differential method. The kinetic parameters (i.e. $k_{\mathrm{TE}}^{\prime}, k_{\mathrm{E}}^{\prime}$, and $k_{\mathrm{E}}^{\prime}$ ) were determined by nonlinear regression fitting using SigmaPlot software (Version 12.3, Systat Software Inc.) and the results are listed in Table 1. The experimental data are fitted by successive approximation method until convergence and tolerance satisfied. The step size and the number of iterations were designed to reduce
Table 1

The fitted values of rate constants of transesterification, forward and reverse esterification at supercritical condition.

\begin{tabular}{llllll}
\hline$T\left({ }^{\circ} \mathrm{C}\right)$ & $k_{\mathrm{TE}}^{\prime}\left(\mathrm{min}^{-1}\right)$ & $k_{\mathrm{E}}^{\prime}\left(\mathrm{min}^{-1}\right)$ & $k_{\mathrm{E}}{ }^{\prime}\left(\mathrm{min}^{-1}\right)$ & $K_{\mathrm{E}}{ }^{\mathrm{a}}$ & $R^{2}$ \\
\hline 250 & 0.32 & 1.90 & 0.58 & 3.28 & 0.99 \\
275 & 0.42 & 2.97 & 0.60 & 4.95 & 0.99 \\
300 & 0.52 & 3.55 & 0.64 & 5.55 & 0.98 \\
325 & 0.96 & 4.42 & 0.68 & 6.50 & 0.97 \\
\hline \multicolumn{7}{r}{ a The equilibrium constant of esterification reaction, defined as $k_{\mathrm{E}}=k_{\mathrm{E}}^{\prime} / k_{\mathrm{E}}^{\prime}$}
\end{tabular}

unnecessary computation without affecting the accuracy of predictions. The initial values of the fitted parameters (i.e. rate constants) were determined for starting the calculation. The constraints for all fitted parameters were greater than zero. The following objective function was applied for minimizing the standard error of estimate (also known as the sum of squares error (SSE)) between actual and predicted values:

$\sigma_{\mathrm{est}}=\sqrt{\frac{\sum\left(Y-Y^{\prime}\right)^{2}}{N}}$

Here $\sigma_{\text {est }}$ is the standard error of estimate, $N$ is the number of experimental data points, $Y$ is the actual or experimentally measured values, and $Y^{\prime}$ is the predicted values.

In Table 1, it was found that the values of $k^{\prime} \mathrm{TE}$ increase with increasing temperature, indicating that higher temperature favors transesterification of triglycerides to methyl esters. An explanation to this point is that high temperature weakens the degree of hydrogen bonding in hydroxyl group of methanol so it becomes less polar compared to liquid methanol at ambient pressure and temperature. As the result, methanol and fatty oil molecules collide more frequently as a result of increased homogeneity in the reaction mixture that facilitated the formation of methyl esters. Increasing temperature also causes the molecules to move around faster because of greater kinetic energy in the system that increases the number of collisions per unit time. Moreover, the increasing value of $k^{\prime}$ TE with temperature also reflects the Arrhenius behavior of transesterification reaction.

The values of $k_{\mathrm{E}}^{\prime}$ and $k_{\mathrm{E}}^{\prime}$ rate constants were also enhanced with increasing temperature, revealing the Arrhenius behavior of forward and reverse esterification reactions. Interestingly, the rate constant of forward esterification is greater than reverse esterification in all temperatures, indicating that the formation of methyl esters is more favorable than hydrolysis reaction. By comparing the values of $k^{\prime}$ TE and $k_{\mathrm{E}}^{\prime}$, it can be concluded that the rate of formation of methyl esters from esterification is faster than transesterification. This may be ascribed to the reaction mechanism involved in the transformation of FFA and TG to FAME that follows $S_{n} 2$ mechanism. In the latter case, the transformation of TG to FAME proceeds in three consecutive steps, which expected to be more energy- and time-consuming during structural orientation and conformation of the reactants and intermediate species on the reaction pathway hence the rate constant of transesterification is slower than esterification with respect to the formation of fatty acid methyl esters. Further evidences of this explanation from thermodynamic consideration will be discussed in the next section.

As comparison, the recently proposed kinetic models of non-catalytic transesterification and esterification and their rate constants are summarized in Table $2[17,19,27,28]$. The magnitude of transesterification rate constants in this work comparable to that of Kusdiana and Saka [19] but considerably higher than that of Song et al. [27] for similar reaction system and the approaches taken in proposing the model. By comparing the rate constants of forward esterification (i.e. methanolysis of FFA to FAME), the values in this work differ greatly to those obtained by Cho et al. [17] and Alenezi et al. [28]. In their studies, Cho et al. [17] and Alenezi et al. [28] 

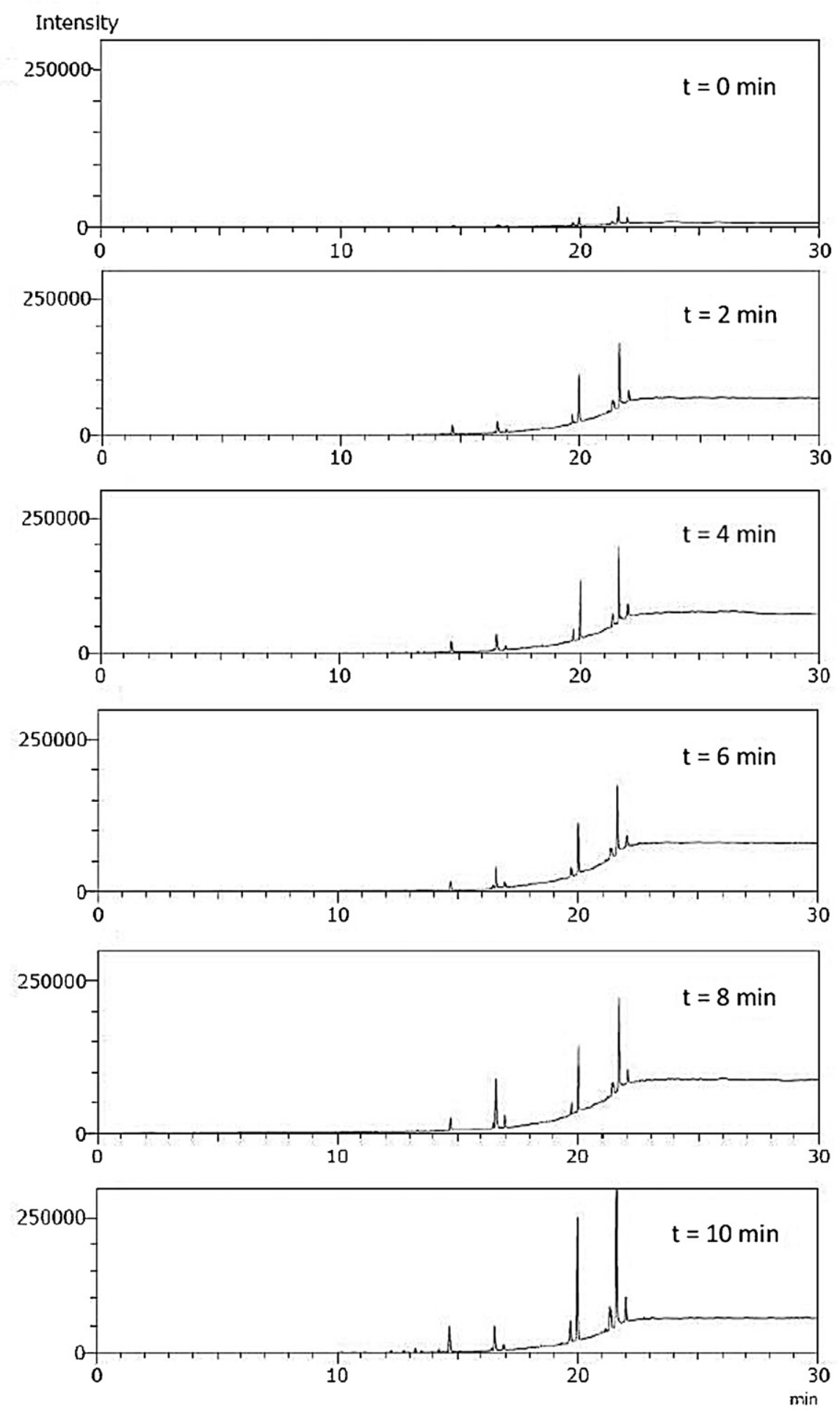

Fig. 5. The chromatograms of methyl ester peaks with variation of reaction time at $12 \mathrm{MPa}$ and $325^{\circ} \mathrm{C}$.

only consider esterification of free fatty acids to model the kinetics of FAME formation while this work also incorporates transesterification of fatty acid esters where simultaneously occurring esterand transesterification were responsible in the FAME formation. Additionally, the composition of feedstock may act as a determining factor toward the rate constants, as confirmed by Rathore and Madras [29].

While high temperatures favored for increasing the conversion efficiency of FFA and TG, it should be known the temperature limit of the process to avoid thermal decomposition of methyl ester species. The dependency of decomposition of methyl esters on temperature has been recently studied by Shin et al. [30] and Quesada-Medina and Olivares-Carrillo [31]. In their studies, it was known that thermal decomposition of polyunsaturated methyl esters containing two or more double-bond (e.g. methyl linoleate and methyl linolenate) start to appear at temperatures about $300^{\circ} \mathrm{C}$ while saturated methyl esters (e.g. methyl palmitate and methyl stearate) hardly decomposed even at temperatures above $350^{\circ} \mathrm{C}$. 
Table 2

A summary of recently reported kinetic models of non-catalytic transesterification and esterification.

\begin{tabular}{|c|c|c|c|c|}
\hline Kinetic model & Approaches & Rate constants & Solution & Reference \\
\hline $\ln \frac{[\mathrm{uME}, t]}{[\mathrm{uME}, 0]}=-k t$ & $\begin{array}{l}\text { Single-step and first-order } \\
\text { transesterification }\end{array}$ & $k=0.042-1.068 \mathrm{~min}^{-1}$ & Integral method & [19] \\
\hline $\begin{array}{l}r_{\mathrm{TG}}=-(4.3376 \times \\
\left.10^{5}\right) \exp \left(-\frac{1.0527 \times 10^{5}}{R T}\right)[\mathrm{TG}]^{0.96}[\mathrm{MeOH}]^{1.05}\end{array}$ & $\begin{array}{l}\text { Single-step, first-order, and } \\
\text { irreversible } \\
\text { transesterification }\end{array}$ & $k=(0.13-2.78) \times 10^{-4} \mathrm{~min}^{-1}\left(\right.$ at $\left.350^{\circ} \mathrm{C}\right)$ & $\begin{array}{l}\text { Fourth-order Runge-Kutta } \\
\text { with Levenberg-Marquardt } \\
\text { algorithm }\end{array}$ & [27] \\
\hline$r_{\mathrm{FFA}}=k_{1}[\mathrm{FFA}][\mathrm{MeOH}]-k_{1}^{\prime}[\mathrm{FAME}]\left[\mathrm{H}_{2} \mathrm{O}\right]$ & $\begin{array}{l}\text { Reversible and first-order } \\
\text { esterification }\end{array}$ & $\begin{array}{l}k_{1}=0.035-0.230 \mathrm{~min}^{-1} \times[\mathrm{mol} / \mathrm{mol} \text { of FFA }]^{-1} \\
k_{1}^{\prime}=0.037-0.063 \mathrm{~min}^{-1} \times[\mathrm{mol} / \mathrm{mol} \text { of FFA }]^{-1}\end{array}$ & $\begin{array}{l}\text { Non-linear optimization } \\
\text { using Microsoft Excel's } \\
\text { Solver Function }\end{array}$ & {$[28]$} \\
\hline $\ln \frac{[\mathrm{FFA}]_{t}}{[\mathrm{FFA}]_{0}}=-k_{f}^{\prime} t$ & $\begin{array}{l}\text { Non-reversible and } \\
\text { first-order esterification }\end{array}$ & $k_{\mathrm{f}}^{\prime}=0.029-0.048 \mathrm{~min}^{-1}$ & Integral method & {$[17]$} \\
\hline $\begin{array}{l}r_{\mathrm{FAME}}=k_{\mathrm{TE}}^{\prime}\left[\mathrm{TG}_{\text {init }}-X_{\mathrm{TG}}\right]+k_{\mathrm{E}}^{\prime}\left[\mathrm{FFA}_{\text {init }}-\right. \\
\left.X_{\mathrm{FFA}}\right]-k_{\mathrm{E}}^{\prime}\left[3 X_{\mathrm{TG}}+X_{\mathrm{FFA}}\right]\left[X_{\mathrm{FFA}}\right]\end{array}$ & $\begin{array}{l}\text { Single-step, pseudo-first } \\
\text { order, and irreversible } \\
\text { transesterification } \\
\text { Reversible esterification }\end{array}$ & $\begin{array}{l}k_{\mathrm{TE}}^{\prime}=0.32-0.96 \mathrm{~min}^{-1} k_{\mathrm{E}}^{\prime}=1.90-4.42 \mathrm{~min}^{-1} \\
k_{\mathrm{E}}^{\prime}=0.58-0.68 \mathrm{~min}^{-1}\end{array}$ & Nonlinear regression fitting & This Work \\
\hline
\end{tabular}

Additionally, exposure time also plays crucial role toward thermal degradation of methyl esters. Shin et al. [30] report that all saturated, mono- and polyunsaturated fatty acid methyl esters remained stable at temperature of $325^{\circ} \mathrm{C}$ or below for exposure time of 20 min while Quesada-Medina and Olivares-Carrillo [31] observe the increasing yield of methyl palmitate, methyl oleate, methyl linoleate, and methyl linolenate at $325^{\circ} \mathrm{C}$ up to exposure time of 60 min.

In order to investigate the degree of methyl esters degradation in this work, the mixture of fatty acid methyl esters produced from two-step transesterification of fatty oil was exposed to supercritical condition at $12 \mathrm{MPa}$ and $325^{\circ} \mathrm{C}$ for 2-30 min with methanol as the medium. The two-step transesterification process was conducted by following experimental procedure described by Alptekin et al. [9] under optimum reaction conditions. The thermal stability profiles of several fatty acid methyl esters in the mixture are depicted in Fig. 6. It can be seen that thermal degradation of all fatty acid methyl ester species still not advanced for exposure time of $10 \mathrm{~min}$ (i.e. the longest transesterification time). The percentage recovery of methyl linoleate and methyl linolenate started to drastically decline for exposure time longer than 15 min while methyl palmitate, methyl stearate, and methyl arachidate insusceptible to thermal degradation up to exposure time of $30 \mathrm{~min}$. Hence, the effect of thermal degradation of fatty acid methyl esters can be ignored in modeling the kinetics of reaction.

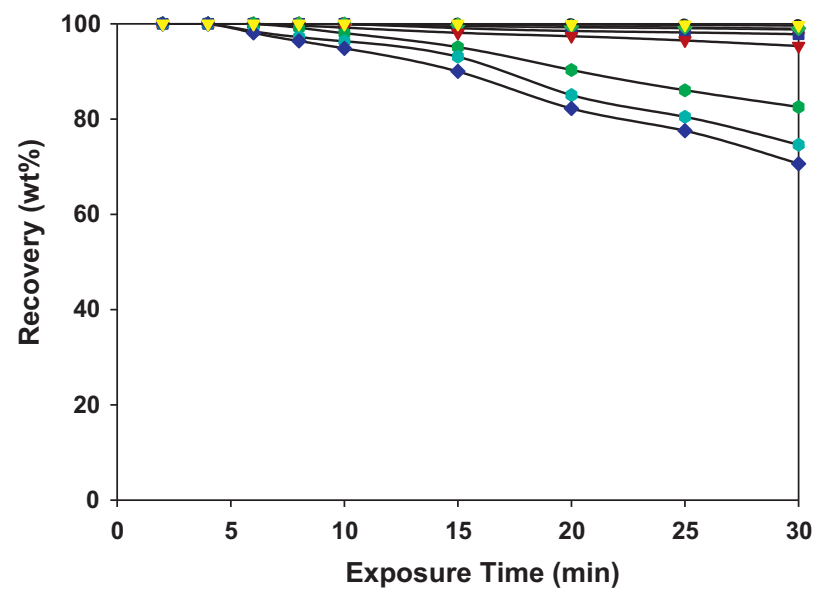

Fig. 6. Thermal behavior of several fatty acid methyl esters in biodiesel at $325^{\circ} \mathrm{C}$ within exposure time of 2-30 min ((A) methyl myristate; $(\bullet)$ methyl palmitate; $(\square)$ methyl palmitolein; $(\bullet)$ methyl heptadecanoate; $(\nabla)$ methyl stearate; $(\mathbf{O})$ methyl oleate; $($ ) methyl linoleate; $(\checkmark)$ methyl linolenate; and $(\nabla)$ methyl arachidate).
The effect of pressure may not be crucial toward the rate constants of supercritical transesterification and esterification. According to the Le Chatelier's principle, the increase of pressure shifts the chemical equilibrium in a direction that lowers the pressure, in other means, to the direction that exhibits less number of moles and vice versa. Because esterification and transesterification reactions have the same number of moles of reactants and products (stoichiometrically equal in both reaction sides), the change of pressure would not affect the chemical equilibrium of the reaction. This effect also applies to supercritical fluid reaction system because of its behavior that resembles gases (i.e. fills and takes the shape of the container). Hence, it can be concluded that the rate constants of esterification and transesterification were unaffected by the change of pressures regarding: (1) the law of action-reaction above and (2) the role of pressure that only serves for tuning the density of fluid (i.e. methanol) in the mixture.

\subsection{Thermodynamic analysis}

Thermodynamic analysis was addressed for evaluating the enthalpy $\left(\Delta H^{\ddagger}\right)$, entropy $\left(\Delta S^{\ddagger}\right)$, and the Gibb’s free energy of activation $\left(\Delta G^{\ddagger}\right)$, which are the important features for interpreting the behavior of transesterification and esterification reactions. In this regard, ACT (activation complex theory), which developed by Eyring in 1935 [32] was applied to evaluate thermodynamic parameters above in conjunction with temperature-dependent rate constant. This theory proposes that any particular chemical reaction proceeded via a transitory energized species of intermediate structure between reactants and products called the activated complex and this complex is in quasi-equilibrium state with the reactants [33], as described below:

$X+Y \leftrightarrow|X \ldots Y|^{\ddagger} \rightarrow$ product

where $X$ and $Y$ are the reactants and the superscript notation $\ddagger$ refers to the activation-state complex. The mathematical relation between rate constants and temperature can be expressed by the following Arrhenius equation:

$k=A \exp \left(-\frac{E_{a}}{R T}\right)$

Taking the natural logarithm of equation above gives:

$\ln k=\ln A-\frac{E_{a}}{R T}$

Here $k$ is the rate constant $\left(\min ^{-1}\right), A$ is the frequency factor or pre-exponential coefficient $\left(\mathrm{min}^{-1}\right), R$ is the universal gas constant $\left(8.314 \mathrm{~J} \mathrm{~mol}^{-1} \mathrm{~K}^{-1}\right), T$ is the absolute temperature $(\mathrm{K})$, and $E_{a}$ is the activation energy $(\mathrm{kJ} / \mathrm{mol})$. The plot of $1 / T$ as abscissa and $\ln k$ as ordinate in Eq. (21) gives a straight line with slope and intercept 


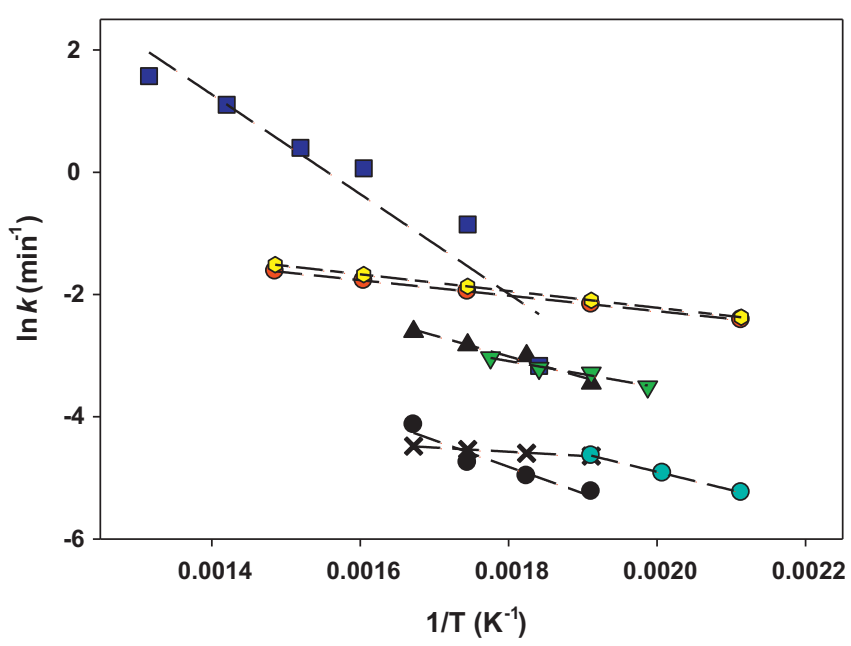

Fig. 7. Overlay of regressed lines (- - -) of Arrhenius plots for supercritical transesterification of $(\bullet)$ tannery waste, $(\square)$ rapeseed oil [19], ( ) Karanja and ( ) Jatropha oils [27], and esterification of leather tanning waste $(\boldsymbol{\Lambda})$ forward, $(\times)$ reverse, $(\nabla)$ PFAD [17], and ( ) oleic acid [35].

of $-E_{a} / R$ and $\ln A$, respectively. The value of Gibb's free energy of activation $\left(\Delta G^{\ddagger}\right)$ can be calculated from Eyring-Polanyi equation [34], which is analog to Arrhenius equation:

$k=\kappa \frac{k_{B} T}{h} \exp \left(-\Delta G^{\ddagger} / R T\right)$

Taking the natural logarithm of equation above and inserting $\Delta G^{\ddagger}=\Delta H^{\ddagger}-T \Delta S^{\ddagger}$ gives:

$\ln \left(\frac{k}{T}\right)=\frac{-\Delta H^{\ddagger}}{R}\left(\frac{1}{T}\right)+\left[\ln \kappa+\ln \left(\frac{k_{B}}{h}\right)+\frac{\Delta S^{\ddagger}}{R}\right]$

where $k_{B}$ and $h$ are the Boltzmann $\left(1.38 \times 10^{-23} \mathrm{JK}^{-1}\right)$ and Planck $\left(6.63 \times 10^{-34} \mathrm{Js}\right)$ constants, respectively. Eq. (23) resembles van't Hoff's equation describing the mathematical relation between enthalpy and entropy of activation with rate constant. The values of enthalpy $\left(\Delta H^{\ddagger}\right)$ and entropy of activation $\left(\Delta S^{\ddagger}\right)$ can be obtained from the slope and the intercept of linear plot of $1 / T \mathrm{vs}$. $\ln (k / T)$. The prefactor $\kappa$ refers to the transmission coefficient and this value is usually taken to be unity in most cases. Originally, Eyring-Polanyi equations (Eqs. (22) and (23)) were developed for kinetic theory of gas phase reaction, but it can be applied to supercritical phase because this phase retains the gas-like transport properties and behaves like a gas.

The Arrhenius plots of transesterification and esterification are displayed in Fig. 7 while the values of corresponding thermodynamic parameters ( $A$ and $E_{a}$ ) are given in Table 3 . The frequency factors of transesterification and forward esterification were higher than reverse esterification, indicating the formation of methyl esters is more predominant than its hydrolysis. In chemical kinetics, the frequency factor $(A)$ describes how often the molecules collide at concentration of 1 mole/ 1 and on whether the molecules are properly oriented during the collisions. Hence, higher value of frequency factor means higher probability of successful collisions (i.e. the collisions that cause chemical change). By comparing the frequency factor between transesterification and forward esterification, it can be concluded that the formation of methyl esters from esterification of free fatty acid is more feasible than transesterification of triglycerides.

The activation energy $\left(E_{a}\right)$ of transesterification, forward and reverse esterification was $36.01 \mathrm{~kJ} / \mathrm{mol}, 28.38 \mathrm{~kJ} / \mathrm{mol}$, and $5.66 \mathrm{~kJ} / \mathrm{mol}$, respectively. Higher activation energy for transesterification caused a slower formation rate of methyl esters compared to esterification. This is likely due to greater steric interactions

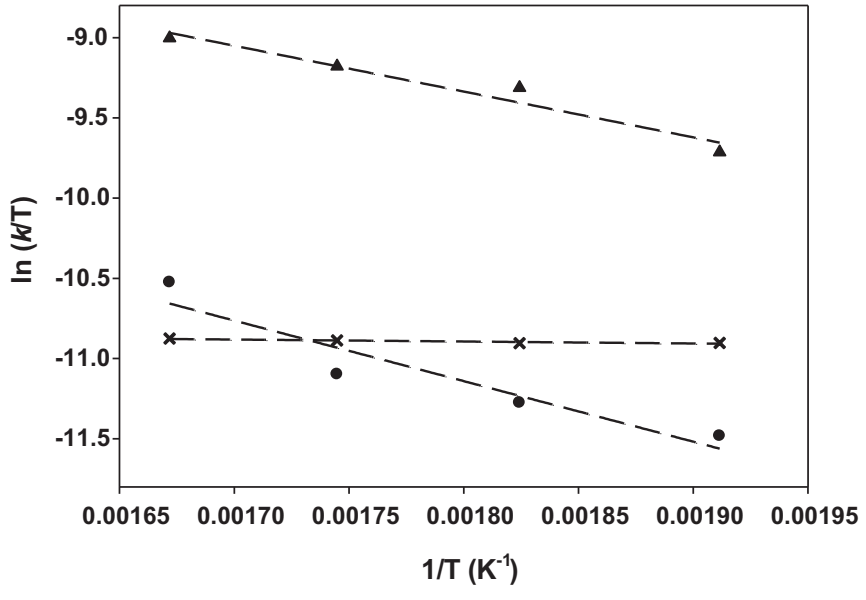

Fig. 8. The Eyring plots of $(\bullet)$ transesterification, $(\boldsymbol{\Delta})$ forward and $(x)$ reverse esterification of leather tanning waste to biodiesel at supercritical condition.

(i.e. intra- and intermolecular van der Waals repulsion) that retard nucleophilic attack on the carbocation of triglyceride by methoxide radicals. Another factor that caused the increase of activation energy is the structural conformation of the transition state involving the changes of bond lengths and bond angles. These two factors were found to be more prominent in triglycerides than FFA due to more complex molecular structure of the former.

As comparison, several reported values of activation energy and frequency factor for non-catalytic transesterification and esterification of various feedstocks with methanol as the reacting alcohol are included in Table 3 and Fig. 7 [17-19,27-29,35-37]. In Table 3, it can be seen that the value of activation energy in this work was much lower than those reported by Kusdiana and Saka [19] and Song et al. [27] for single-step transesterification of rapeseed oil and RBD palm oil, respectively, but comparable to that of Varma and Madras [35] for supercritical transesterification of castor oil at temperature range of $200-350^{\circ} \mathrm{C}$ and pressure of $20 \mathrm{MPa}$. The variation of activation energy values is strongly related to the rate constants, which is inversely proportional to the activation energy. In this context, higher activation energy corresponds to a slower reaction rate and vice versa. The dependence of activation energy toward rate constants was also revealed in Fig. 7. The slope of the regressed lines of Arrhenius plots for transesterification of leather tanning waste and rapeseed oil [19] is steeper than those of Karanja oil and Jatropha oil [29], indicating greater temperature sensitivity of the rate constants in the former than the latter. In other hand, the slopes of the regressed lines for esterification of leather tanning waste, PFAD [17], and oleic acid [37] are similar. Meanwhile, there is no clear relationship actually between the rate constants and frequency factor, at least theoretically. However, it should be kept in mind that the reacting molecules should be correctly oriented and had enough the internal energy (above the activation energy) to undergo a particular reaction.

Fig. 8 depicts the Eyring plots of transesterification and esterification and the values of activation parameters (i.e. $\Delta G^{\ddagger}, \Delta H^{\ddagger}$, and $\Delta S^{\ddagger}$ ) are listed in Table 4 . The values of enthalpy of activation of transesterification, forward and reverse esterification were $40.66 \mathrm{~kJ} / \mathrm{mol}, 34.23 \mathrm{~kJ} / \mathrm{mol}$, and $10.9 \mathrm{~kJ} / \mathrm{mol}$, respectively, indicating that energy input (heat) from external source is required to raise the energy level and transform the reactants to their transition state. The values of entropy of activation $\left(\Delta S^{\ddagger}\right)$ were negative in all corresponding reactions, which is in conformance with previous studies [17-20]. The negative values of $\Delta S^{\ddagger}$ may arise as a result of associative mechanism, which means that the reactant species joined each other to form transition state along the reaction pathway. Hence, the transition state has more ordered structure 
Table 3

The Arrhenius parameters of non-catalytic transesterification and esterification.

\begin{tabular}{|c|c|c|c|c|c|c|}
\hline Reaction model & Feedstock & $T\left({ }^{\circ} \mathrm{C}\right)$ & $E_{a}(\mathrm{~kJ} / \mathrm{mol})$ & $A\left(\mathrm{~min}^{-1}\right)$ & $R^{2}$ & References \\
\hline Single-step transesterification & Tannery waste & $250-325$ & 36.01 & 1176.67 & 0.92 & This work \\
\hline Forward esterification & & & 28.38 & 1372.98 & 0.97 & \\
\hline Reverse esterification & & & 5.66 & 2.11 & 0.99 & \\
\hline Single-step transesterification & Palm olein oil & $270-350$ & 81.37 & not reported & 0.98 & {$[18]$} \\
\hline Single-step Transesterification & Rapeseed oil & $200-500$ & $67.76^{\mathrm{a}}$ & $3.21 \times 10^{5 \mathrm{a}}$ & 0.89 & [19] \\
\hline Single-step transesterification & RBD palm oil & 350 & $105^{\mathrm{b}}$ & Not reported & 0.96 & [27] \\
\hline \multirow[t]{2}{*}{ Single-step transesterification } & Jatropha oil & $200-400$ & 11.37 & 101.02 & 0.99 & [29] \\
\hline & Karanja oil & & 10.54 & 78.21 & 0.99 & \\
\hline Single-step transesterification & Sunflower oil & $250-350$ & 3.00 & Not reported & - & {$[36]$} \\
\hline \multirow[t]{2}{*}{ Single-step transesterification } & Linseed oil & $200-350$ & 46.50 & 4.68 & 0.99 & [35] \\
\hline & Castor oil & & 35.00 & 32.4 & 0.99 & \\
\hline Esterification & Oleic acid & $200-250$ & 24.80 & 2.90 & 0.99 & [37] \\
\hline Esterification & $\mathrm{PFAD}^{\mathrm{c}}$ & $230-290$ & 17.74 & 2.12 & 0.97 & [17] \\
\hline Forward esterification & Free fatty acids & $250-320$ & 72 & $5.00 \times 10^{5}$ & 0.98 & [28] \\
\hline Reverse esterification & & & 23.2 & 7.90 & 0.97 & \\
\hline
\end{tabular}

a Calculated from $k$ values in the temperature range of $270-487^{\circ} \mathrm{C}$ listed in Table 1 of Ref. [19].

b Determined from numerical analysis by Levenberg-Marquardt algorithm.

c Palm Fatty Acid Distillate, a by-product from crude palm oil refinery with FFA contents of $87.3 \%$.

Table 4

The Eyring activation parameters of transesterification and esterification reactions at supercritical condition.

\begin{tabular}{|c|c|c|c|c|c|}
\hline Reaction & $T(\mathrm{~K})$ & $\Delta G^{\ddagger}(\mathrm{kJ} / \mathrm{mol})$ & $\Delta H^{\ddagger}(\mathrm{kJ} / \mathrm{mol})$ & $\Delta S^{\ddagger}(\mathrm{J} / \mathrm{mol} \mathrm{K})$ & $R^{2}$ \\
\hline Transesterification & $\begin{array}{l}523.15 \\
548.15 \\
573.15 \\
598.15\end{array}$ & $\begin{array}{l}153.64 \\
159.48 \\
165.32 \\
171.16\end{array}$ & 31.37 & -233.71 & 0.90 \\
\hline Forward esterification & $\begin{array}{l}523.15 \\
548.15 \\
573.15 \\
598.15\end{array}$ & $\begin{array}{l}145.34 \\
151.15 \\
156.96 \\
162.77\end{array}$ & 23.74 & -232.43 & 0.95 \\
\hline Reverse esterification & $\begin{array}{l}523.15 \\
548.15 \\
573.15 \\
598.15\end{array}$ & $\begin{array}{l}150.79 \\
157.94 \\
165.10 \\
172.26\end{array}$ & 1.02 & -286.28 & 0.97 \\
\hline
\end{tabular}

than the reactants in the ground state, accordingly a negative value of entropy of activation. The degree and spontaneity of chemical reactions can be denoted from the Gibb's free energy of activation $\left(\Delta G^{\ddagger}\right.$ ) parameter. As denoted in Table 4 , the positive values of $\Delta G^{\ddagger}$ were observed in all reactions, revealing endergonic and unspontaneous characteristics. Furthermore, the positive value of $\Delta G^{\ddagger}$ may be ascribed to the higher energy level in the transition state than in the reactant species.

\section{Conclusions}

The production of biodiesel from leather tanning waste with high free fatty acid content by methanolysis reaction at supercritical condition has been demonstrated in this work. The supercritical transesterification experiments were conducted at $12 \mathrm{MPa}$ and methanol/fatty oil molar ratio of $40: 1$ with variation of temperatures from $250^{\circ} \mathrm{C}$ to $325^{\circ} \mathrm{C}$. The proposed semi-empirical kinetic model of formation of fatty acid methyl esters incorporating reversible esterification and non-reversible transesterification fitted well with experimental results. Nonlinear regression fitting can be used as an alternative technique for determining reaction rate constants rather than applying numerical analysis with a complex algorithm and an elaborate computation. The activation energy of transesterification, forward and reverse esterification was $36.01 \mathrm{~kJ} / \mathrm{mol}, 28.38 \mathrm{~kJ} / \mathrm{mol}$, and $5.66 \mathrm{~kJ} / \mathrm{mol}$, respectively. Thermodynamic activation parameters of the reactions (i.e. $\Delta G^{\ddagger}, \Delta H^{\ddagger}$, and $\Delta S^{\ddagger}$ ) were evaluated based on activation complex theory (ACT) and positive values of $\Delta G^{\ddagger}$ and $\Delta H^{\ddagger}$ and negative values of $\Delta S^{\ddagger}$ were obtained, revealing the unspontaneous, endergonic, and endothermic characteristics of transesterification and esterification at supercritical condition.

\section{Acknowledgments}

The Australian Research Council (ARC) is acknowledged for financial support under the ARC Future Fellow Program (FT100100879).

\section{References}

[1] N.S. Kasim, T.H. Tsai, S. Gunawan, Y.H. Ju, Biodiesel production from rice bran oil and supercritical methanol, Bioresource Technology 100 (2009) 2399-2403.

[2] F.O. Licht, World ethanol and biofuels report, in: L.S. Brown (Ed.), World on the Edge: How to Prevent Environmental and Economic Collapse, W.W. Norton \& Co, New York, 2011, p. 265.

[3] D.D.C. Barbosa, T.M. Serra, S.M.P. Meneghetti, M.R. Meneghetti, Biodiesel production by ethanolysis of mixed castor and soybean oils, Fuel 89 (2010) 3791-3794.

[4] R. Chakraborty, S. Bepari, A. Banerjee, Transesterification of soybean oil catalyzed by fly ash and egg shell derived solid catalysts, Chemical Engineering Journal 165 (2010) 798-805.

[5] A.K. Endalew, Y. Kiros, R. Zanzi, Inorganic heterogeneous catalysts for biodiesel production from vegetable oils, Biomass and Bioenergy 35 (2011) 3787-3809.

[6] E. Alptekin, M. Canakci, Optimization of pretreatment reaction for methyl ester production from chicken fat, Fuel 89 (2010) 4035-4039.

[7] J.M. Encinar, N. Sanchez, G. Martinez, L. Garcia, Study of biodiesel production from animal fats with high free fatty acid content, Bioresource Technology 102 (2010) 10907-10914.

[8] M.J. Haas, T.A. Foglia, Alternate feed stocks and technologies for biodiesel production, in: G. Knothe, J. Krahl, J.V. Gerpen (Eds.), Biodiesel Handbook, AOCS Press, Illinois, 2005, pp. 42-61.

[9] E. Alptekin, M. Canakci, H. Sanli, Evaluation of leather industry wastes as a feedstock for biodiesel production, Fuel 95 (2012) 214-220. 
[10] K. Kolomaznik, M. Barinova, T. Furst, Possibility of using tannery waste for biodiesel production, Journal of the American Leather Chemists Association 104 (2009) 177-182.

[11] H. Ozgunay, S. Colak, G. Zengin, O. Sari, H. Sarikahya, L. Yuceer, Performance and emission study of biodiesel from leather industry pre-fleshings, Waste Management 27 (2007) 1897-1901.

[12] M. Canakci, The potential of restaurant waste lipids as biodiesel feedstocks, Bioresource Technology 98 (2007) 183-190.

[13] Y.Warabi, D. Kusdiana, S. Saka, Reactivity of triglycerides and fatty acids of rapeseed oil in supercritical alcohols, Bioresource Technology 91 (2004) 283-287.

[14] R. Sawangkeaw, K. Bunyakiat, S. Ngamprasertsith, A review of laboratoryscale research on lipid conversion to biodiesel with supercritical methanol (2001-2009), Journal of Supercritical Fluids 55 (2010) 1-13.

[15] E. Minami, S. Saka, Kinetics of hydrolysis and methyl esterification for biodiesel production in two-step supercritical methanol process, Fuel 85 (2006) 2479-2483.

[16] S.A. D'lppolito, J.C. Yori, M.E. Iturria, C.L. Pieck, C.R. Vera, Analysis of a two-step, noncatalytic, supercritical biodiesel production process with heat recovery, Energy and Fuels 21 (2007) 339-346.

[17] H.J. Cho, S.H. Kim, S.W. Hong, Y.K. Yeo, A single step non-catalytic esterification of palm fatty acid distillate (PFAD) for biodiesel production, Fuel 93 (2012) 373-380.

[18] C.S. Choi, J.W. Kim, C.J. Jeong, H. Kim, K.P. Yoo, Transesterification kinetics of palm olein oil using supercritical methanol, Journal of Supercritical Fluids 58 (2011) 365-370.

[19] D. Kusdiana, S. Saka, Kinetics of transesterification in rapeseed oil to biodiesel fuel as treated in supercritical methanol, Fuel 80 (2001) 693-698.

[20] H. He, S. Sun, T. Wang, S. Zhu, Transesterification kinetics of soybean oil for production of biodiesel in supercritical methanol, Journal of the American Oil Chemists Society 84 (2007) 399-404.

[21] S.B. Glisic, A.M. Orlovic, Modelling of non-catalytic biodiesel synthesis under sub and supercritical conditions: the influence of phase distribution, Journal of Supercritical Fluids 65 (2012) 61-70.

[22] K. Bunyakiat, S. Makmee, R. Sawangkeaw, S. Ngamprasertsith, Continuous production of biodiesel via transesterification from vegetable oils in supercritical methanol, Energy and Fuels 20 (2006) 812-817.

[23] S. Espinosa, T. Fornari, S.B. Bottini, E.A. Brignole, Phase equilibria in mixtures of fatty oils and derivatives with near critical fluids using the GC-EOS model, Journal of Supercritical Fluids 23 (2002) 91-102.
[24] T. Srinophakun, B. Phithakchokchai, Phase equilibrium modeling of triglycerides in supercritical fluids, Journal of Chemical Thermodynamics 43 (2011) 471-478.

[25] T. Holderbaum, J. Gmehling, PSRK: a group contribution equation of state based on UNIFAC, Fluid Phase Equilibria 70 (1991) 251-265.

[26] V.F. Marulanda, G. Anitescu, L.L. Tavlarides, Investigations on supercritica transesterification of chicken fat for biodiesel production from low-cost lipid feedstocks, Journal of Supercritical Fluids 54 (2010) 53-60.

[27] E.S. Song, J.w. Lim, H.S. Lee, Y.W. Lee, Transesterification of RBD palm oil using supercritical methanol, Journal of Supercritical Fluids 44 (2008) 356-363.

[28] R. Alenezi, G.A. Leeke, J.M. Winterbottom, R.C.D. Santos, A.R. Khan, Esterification kinetics of free fatty acids with supercritical methanol for biodiesel production, Energy Conversion and Management 51 (2010) 1055-1059.

[29] V. Rathore, G. Madras, Synthesis of biodiesel from edible and non-edible oils in supercritical alcohols and enzymatic synthesis in supercritical carbon dioxide, Fuel 86 (2007) 2650-2659.

[30] H.Y. Shin, S.M. Lim, S.Y. Bae, S.C. Oh, Thermal decomposition and stability of fatty acid methyl esters in supercritical methanol, Journal of Analytical and Applied Pyrolysis 92 (2011) 332-338.

[31] J. Quesada-Medina, P. Olivares-Carrillo, Evidence of thermal decomposition of fatty acid methyl esters during the synthesis of biodiesel with supercritical methanol, Journal of Supercritical Fluids 56 (2011) 56-63.

[32] H. Eyring, The activated complex in chemical reactions, Journal of Chemica Physics 3 (1935) 63-71.

[33] K.J. Laidler, Chemical Kinetics, 3rd ed., Harper-Collins Publishers, New York, 1987.

[34] M.G. Evans, M. Polanyi, Some applications of the transition state method to the calculation of reaction velocities, especially in solution, Transactions of the Faraday Society 31 (1935) 875-894.

[35] M.N. Varma, G. Madras, Synthesis of biodiesel from castor oil and linseed oil in supercritical fluids, Industrial and Engineering Chemistry Research 46 (2007) $1-6$.

[36] G. Madras, C. Kolluru, R. Kumar, Synthesis of biodiesel in supercritical fluids Fuel 83 (2004) 2029-2033.

[37] N.H. Joelianingsih, S. Hagiwara, Y. Sagara, T.H. Soerawidjaya, A.H. Tambunan, K Abdullah, Performance of a bubble column reactor for the non-catalytic methy esterification of free fatty acids at atmospheric pressure, Journal of Chemica Engineering of Japan 40 (2007) 780-785. 